\title{
Matching disruptive innovation paths with entrepreneurial networks: a new perspective on startups' growth with Chinese evidence
}

\author{
Weizhen $\mathrm{Yu}^{1,2,3} \cdot$ Shuanping Dai ${ }^{4,5} \cdot$ Feng Liu $^{6}$ (D) Yi Yang $^{7}$ (D)
}

Received: 16 March 2020 / Revised: 30 August 2021 / Accepted: 20 January 2022

(c) The Author(s) 2022

\begin{abstract}
This study examines the impacts of entrepreneurial networks on startups' performance with a sample of 618 startups in China's Yangtze River Delta region, focusing on matching disruptive innovation paths with network types. The results indicate that entrepreneurial networks (both heterogeneous and homogeneous) are meaningful for startups' growth performance. The study finds that startups exploring lowend disruption may benefit more from heterogeneous peers and avoid networking with an abundance of homogeneous peers. However, if exploring new markets, both types of networks could provide positive impacts. The asymmetric mediation effects of disruptive innovation paths highlight the core of leveraging entrepreneurial networks, whether homogeneous or heterogeneous, is to activate network resources with proper disruption paths.
\end{abstract}

Keywords Startups' growth · Entrepreneurial networks · Disruptive innovation

Shuanping Dai

shuanping.dai@uni-due.de

1 School of Business, Zhejiang University City College, Hangzhou, China

2 Zigong Innovation Center, Zhejiang University, Hangzhou, China

3 Institute of Digital Finance, Zhejiang University City College, Hangzhou, China

4 School of Economics, Jilin University, Changchun, China

5 Institute of East Asian Studies, University of Duisburg-Essen, Duisburg, Germany

6 Business School, Shandong University, Weihai, China

7 Global Leaders College, Yonsei University, Seoul, Republic of Korea 


\section{Introduction}

Entrepreneurial networks help startups gain technology and knowledge, access credit and social resources, manage market uncertainties, and achieve success (Aldrich \& Zimmer, 1986; Dyer \& Singh, 1998; Partanen et al., 2020; Stuart \& Sorenson, 2007; Uzzi, 1997, 1999; Watson, 2007). In this line of research, the studies on the impacts of network structure on networking firms' performance have provided comprehensive insights into entrepreneurship (Hite \& Hesterly, 2001; Hoang \& Antoncic, 2003; Phelps, 2010; Porter \& Woo, 2015). However, we do not fully understand, for example, the underlying motivation and content of entrepreneurial networks, and the association between network types and specific innovation strategies.

This study, departing from the network-driven entrepreneurial effectuation concept (Kerr \& Coviello, 2019, 2020; Sarasvathy, 2001, 2008), proposes that entrepreneurial networks should be integrated into the specific context of the entrepreneurial activities, and the characteristics of the networks should be matched with the essential attributes of innovation paths. Thus, we aim to deepen the understanding of startups' growth by focusing on how to match disruptive innovation paths with entrepreneurial networks. A disruptive innovation strategy is a practical way for a startup to approach success (Majumdara et al., 2018; Yu \& Hang, 2010). Disruptive innovators focus on the long-tail customers, who are the sizable low-purchase power customers that mainstream incumbents overlook (Dai \& Taube, 2020) and may reach the mainstream market section until updating their standards (Christensen, 1997; Christensen et al., 2015; Christensen et al., 2018). Specifically, this study addresses whether disruption paths require different entrepreneurial networks to make startups successful. In this regard, on the basis of Clayton Christensen's (1997, 2006) well-established classification, we study two disruptive innovation paths: (a) the low-end disruption that promotes new products to price-sensitive customers who have consumed old products on the market due to a lower price, and (b) the new-market disruption that aims to expand the market, which often starts with a new fringe-market segment by promoting new products (for more elaboration on the conceptualization, see, e.g., Christensen et al., 2015).

We measure two types of entrepreneurial networks for each startup: heterogeneous and homogeneous. A heterogeneous network refers to the startup diversifying its linkages in terms of its products, technology, origin, culture, and market. A homogeneous network indicates how the startup interacts with the interconnected actors within similar industries, cultural backgrounds, regional distributions, research directions, and target markets. We do not take a stance on the possible trade-offs between heterogeneous networks and homogeneous networks; rather, we investigate both networks in different disruptive innovation contexts. This study examines the the association between entrepreneurial networks, dispruptive innovation strategies, and startups' performance, with a sample of 618 startups in China's Yangtze River Delta region. All sample firms were younger than eight years. We collected data using a 5-point Likert scale questionnaire and calculated the variables using the scale's average values. 
This study contributes to the literature on entrepreneurial networks and startup performance in the following towfold. First, the matching perspective, i.e., matching disruptive paths with entrepreneurial network types, indicates that startups should have a distinctive view regarding networking resources, in particular, as they collect available resources to create possible artifacts in the entrepreneurial effectuation process (Kerr \& Coviello, 2019). Compared to the mature incumbents who dislike networking with homogeneous peers, startups may learn that both types of entrepreneurial networks are useful for them, although the networks function differently as adopting different disruption paths. This finding highlights that startups must match their limited resources with their disruption needs and survival targets, linking to other organizations and individuals strategically at the early entrepreneurial stage. Second, by investigating the mediation effects of disruptive innovation paths, we specify a unique angle to interpret the linkage between entrepreneurial networks and performance. We find that startups exploring low-end disruption may benefit more from heterogeneous peers and avoid networking with an abundance of homogeneous peers. However, if exploring new markets, both types of networks could provide positive impacts. Such asymmetric mediation effects of disruptive innovation strategies demonstrate that the core of utilizing entrepreneurial networks, whether homogeneous or heterogeneous, is to activate network resources with proper disruption paths.

The remainder of the paper proceeds as follows: Sect. "Network driven entrepreneurial effectuation and hypotheses development" considers the theoretical background and develops hypotheses. Section "Research methodology" introduces the research design and data set. Section "Analysis and results" presents the empirical analysis results, and Sect. "Discussion and managerial implications" follows with further discussions and managerial implications. The final section concludes and discusses the study's limitations.

\section{Network-driven entrepreneurial effectuation and hypotheses development}

\section{Entrepreneurial effectuation as a network-driven phenomenon}

Entrepreneurial studies have been experiencing a fundamental shift from the causation logic, which understands entrepreneurship as accomplishing a target by collecting required means, to the effectuation logic, which understands entrepreneurship as collecting the given available means to create possible artifacts, since the works of Sarasvathy $(2001,2008)$. Entrepreneurship embeds in the social networks of entrepreneurs and firms (Dyer \& Singh, 1998; Rogers, 2004). Relying on network resources, startups can obtain additional and diverse resources, opportunities, and human capital to accomplish complex tasks (Cardon et al., 2017; Elfring \& Hulsink, 2003; Ozdemir et al., 2016). A collaborative network functions as an opportunity set (Park et al., 2010; Shu et al., 2018), integrating various internal and external resources (Gulati, 1999; Schoonjans et al., 2013), and diminishing the risk 
of opportunistic behavior (Molina-Morales \& Martinez-Fernandez, 2010). However, networking can sometimes cause unfavorable consequences (Lin \& Si, 2010).

Entrepreneurial networks shape startups' fundamental environments. It is generally assumed that networks comprise two types of formations: heterogeneous and homogeneous. Heterogeneous networks are the primary approach for startups to acquire various external resources (Stuart \& Sorenson, 2007; Witt, 2004). First, heterogeneous networks provide enterprises with various accessible network relationships (not necessarily with entrepreneurs) and knowledge resources, which can bring non-redundant and complementary knowledge and magnify the combination of innovative elements (Grigoriou \& Rothaermel, 2017). Second, frequent interactions and communication among networking members with high heterogeneity can stimulate the willingness of enterprises and networked members to actively establish cooperative relationships and enhance communication (Corsaro et al., 2012; Uzzi, 1997). The startups within the networks may have more possibilities to generate and create new ideas by combining various knowledge from networking peers (Smith \& Tushman, 2005). Notably, the varieties of communication and practices may create a solid foundation for establishing long-term sustainable competitiveness (Carayannis \& von Zedtwitz, 2005). Nevertheless, heterogeneity may also require extra efforts from networking actors to address conflicting business culture and interests and, in turn, may affect startups' performance negatively (Goerzen \& Beamish, 2005).

Networking among homogeneous peers can promote the exchange of proprietary, implicit capabilities as well as mutual knowledge among the various actors and lower resource-flow barriers in competitive factor markets. With homogeneous partners, startups bear fewer transaction costs in communication (Forbes et al., 2006; Martinez \& Aldrich, 2011) and have more possibilities to establish strong and close ties (Smith et al., 2012). However, if entrepreneurs establish networks with "whom I know," the networks may constrain effectuation and insulate firms from innovative information and resources that facilitate outstanding performance (Kerr \& Coviello, 2020; Perry-Smith \& Mannucci, 2015). In other words, they may severely limit their development and opportunities. Taking support from these comparative results, we propose the first hypothesis.

Hypothesis 1 Entrepreneurial networks - both heterogeneous (H1a) and homogeneous (H1b) - positively affect startups' performance.

\section{Disruptive innovation and startups' growth}

Disruptive innovation refers to the fact that startups can adopt paths that the mainstream market actors (including merchants and customers) ignore. Thus, they can achieve catch-up success via focusing on the low-end customers and new markets (Christensen, 1997). Startups usually lack the necessary resources and must deal with uncertainties and operational risks that are not typical to incumbents. Disruptive innovation approaches require fewer entrepreneurial resources, may reduce technical risks, and weaken market competition, providing the most essential and favorable conditions for startups (Chen et al., 2017; Dai \& Taube, 2020). Through 
differentiation and low-cost strategies, startups can open up new development opportunities so that they do not have to challenge the mainstream market (Christensen \& Raynor, 2003; Christensen et al., 2002; Kenagy \& Christensen, 2002). Within the context of complex production systems, entrepreneurs should actively seek proper disruptive solutions rather than waiting for technological breakthroughs (Christensen et al., 2010). Dedehayir et al. (2014) have found that a disruptive change may enjoy more profits than the incumbents can. The above studies lead to the following hypothesis.

Hypothesis 2 Disruptive innovation, including low-end disruption (H2a) and newmarket disruption (H2b), may impose positive impacts on startups' performance.

\section{Entrepreneurial networks and disruptive innovation}

Entrepreneurial networks, as an open structure, provide an organizational function and coordination platform among peers. Similarly, the networks can facilitate disruptive innovation (Hoang \& Antoncic, 2003). With cases in China, Chen et al. (2017) have revealed that external knowledge from firms' networks positively affects low-end disruption. As a company's network density and connections between enterprises grow, it can increase knowledge, learning effects, and the disruption it achieves (Schilling \& Phelps, 2007). Second, via the interactions within entrepreneurial networks, startups, often communicate with unique partners and then create unique combinations of technology and other resources (Ozcan \& Eisenhardt, 2009; Suseno, 2018). These interactions and collaborations can help companies understand each other, further enhancing their strategic profile and helping new ventures develop better solutions for launching new products. In particular, regarding its complex effectuation process, Landry et al. (2002) find that diverse forms of social networks determine the likelihood and magnitude of innovation in firms.

The diversified information and resources shared by heterogeneous networking peers, which may deepen firms' understanding of the market, can help the new ventures grasping entrepreneurial opportunities more efficiently, and improve disruptive innovation performance (Grigoriou \& Rothaermel, 2017; Kumaraswamy et al., 2018). Spontaneous communication among the members of heterogeneous networks automatically extends knowledge sources, enabling startups to improve their capacities to develop knowledge and technology, as well as acquire other resources. Thus, with expanded possibilities, startups may establish a unique value network and business model that may attract mainstream customers and ultimately promote disruptive innovation (Cozzolino et al., 2018).

Homogeneous networks and disruptive innovations also may associate closely. New ventures can fully share resources and learn from the experiences of others with similar endowments and features within the homogeneous networks. Because of the fewer barriers to cognition and communication among the members, these ventures can readily agree upon aggressiveness and risk-taking strategies (Watson et al., 1993). This collaboration, to a certain extent, reduces the difficulties that companies face in developing new markets and establishing value networks. Meanwhile, 
the high degree of homogeneity among members exacerbates industry competition in gaining competitive advantages, which, in turn, may accelerate technological progress and update the entire industry (Cozzolino et al., 2018). By examining the evolution of Voice over Internet Protocol (VoIP) services, Hynes and Elwell (2016) have found that networks among firms are not always functioning to expand disruptive innovation because excluding homogeneous incumbents in the market from the networks poses a considerable challenge. Based on these relationships, the third hypothesis is proposed:

Hypothesis 3 Entrepreneurial networks, including heterogeneous networks and homogeneous networks, may positively affect low-end disruption and new-market disruption.

H3a heterogeneous networks may positively affect low-end disruption.

H3b heterogeneous networks may positively affect new-market disruption.

H3C homogeneous networks may positively affect low-end disruption.

H3d homogeneous networks may positively affect new-market disruption.

\section{Mediating effects of disruptive innovation paths}

Entrepreneurial networks enable startups and interconnected actors to explore and integrate resources for better performance; however, extensive investigations (e.g., Dyer \& Singh, 1998; Elfring \& Hulsink, 2003; Partanen et al., 2020) have demonstrated that accessing external resources cannot guarantee success. Entrepreneurial success, therefore, requires entrepreneurs to not only access external resources through their connections but also to precisely understand the changing needs that endogenously associate with firms' innovation paths and business strategies at the different venture stages. Thus, knowing how to match partners actively and build a cost-effective entrepreneurial network purposefully are vital strategic decisions (Baron \& Tang, 2011).

The association between entrepreneurial networks and firms' performance, therefore, may be mediated by disruptive innovation paths. Networking behavior evolves as entrepreneurs' cognition and evaluation change (Engel et al., 2017; Kaandorp et al., 2020; Porter \& Woo, 2015). As entrepreneurial opportunity appears, startups are usually primarily constrained by their own endowments and make identity-based ties. Later, they gradually shift to make calculated connections that provide greater resource availability and mitigate more uncertainty (Hite \& Hesterly, 2001). Martinez and Aldrich (2011) have found that strong ties do not bring significant innovation levels at the early stage of starting a business; however, they may provide favorable conditions for recruiting and accessing resources for firms. Balancing cohesion and diversity become a must-learn for entrepreneurs. Hence, avoiding the 
potential competition from entrepreneurial networks must be an inevitable question to consider when acquiring a disruption path.

Meanwhile, changing technologies also affect social-organizational dynamics. Soh and Roberts (2003) have found that the stability and evolution of firm networks are punctuated by continuous technological progress. In this context, we may assume that disruptive innovation paths that startups take may impose impacts on their networking strategy as well. Zhang et al. (2019) have found that China's homeappliance company, Haier, as a latecomer, has strategically extended its network corresponding to the evolving market position. We suggest that entrepreneurial networks do not have a simple direct relationship with a startup's performance. Instead, the relationship is achieved through a certain mediator. That is, entrepreneurial networks have an impact on disruptive innovation, and disruptive paths remain important factors affecting startups' performance. Hence, taking support from the above studies, we propose the following:

Hypothesis 4. Disruptive innovation mediates the relationship between entrepreneurial networks and startups' performance.

H4a Low-end disruption mediates the relationship between heterogeneous networks and startups' performance.

H4b Low-end disruption mediates the relationship between homogeneous networks and startups' performance.

H4c New-market disruption mediates the relationship between heterogeneous networks and startups' performance.

H4d New-market disruption mediates the relationship between homogeneous networks and startups' performance.

In summary, the theoretical framework is described in Fig. 1. We aim to scrutinize the association between the two types of entrepreneurial networks and startups' performance and further identify the mediating effects of the two types of disruptive innovation. This framework fits into the classic structure-conduct-performance (SCP) paradigm because we can treat entrepreneurial networks as structural elements and adopt specific disruptive innovation strategies as the conduct of startups.

\section{Methodology}

\section{Data collection and sampling strategy}

The present study employs a questionnaire approach to collect data. The sampled firms were founded within the past 8 years in the Yangtze River Delta region. We designed the preliminary questionnaire based on well-cited literature, tested it on a 


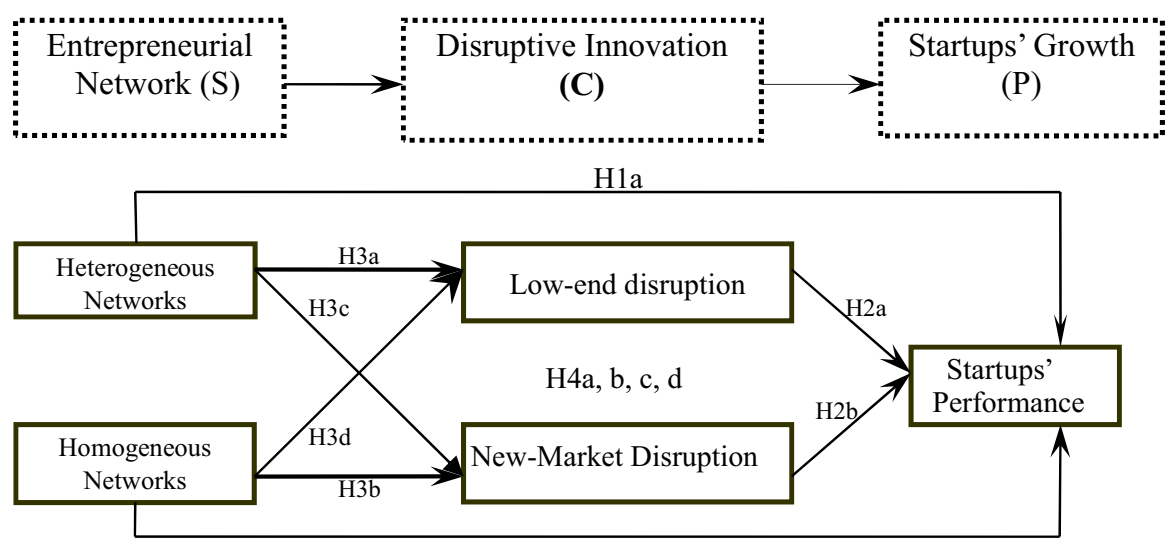

$\mathrm{H} 1 \mathrm{~b}$

Fig. 1 The research framework of startups' growth based on the SCP paradigm

small scale, and revised and finalized it according to company and expert suggestions and feedback.

We conducted the survey from December 2018 to February 2019, distributed 1,000 questionnaires randomly through field interviews, local high-tech park administration offices, point-to-point online surveys, as well as MBA, EMBA, and DBA classes. We received 820 questionnaires (response rate $82 \%$ ), of which 618 were valid (validity rate $75.4 \%$ ) after eliminating the incomplete ones. Table 1 shows the samples' descriptive statistics.

The performance of surveyed firms followed a normal distribution and is representative. All variables were measured using a 5-point Likert scale ranging from 1 (strongly disagree) to 5 (strongly agree). For example, we asked, "Did your firm perform better than your peers?" The firm's performance may receive a subjective evaluation between 1 (strongly disagree) and 5 (strongly agree). We calculated the average scale of all variables, including the performance of startups, independent variables, and control variables.

\section{Measures}

\section{Dependent variable: performance of startups}

Following previous studies' suggestions (Baum et al., 2001; Singh et al., 2016; Stam et al., 2014), the present study adopts five subjective comparative performance indicators relative to their primary peers in the market, including (a) the number of employees, (b) sales, (c) the growth rate of new products or new services, (d) market profit, and (e) market share-instead of objective performance-to measure firms' growth. One example statement is, "Compared to its peers, in the last three years, your firm has had more significant sales growth." The respondents assessed each of these items on a five-point scale ranging from 1 (strongly disagree) to 5 (strongly agree). 


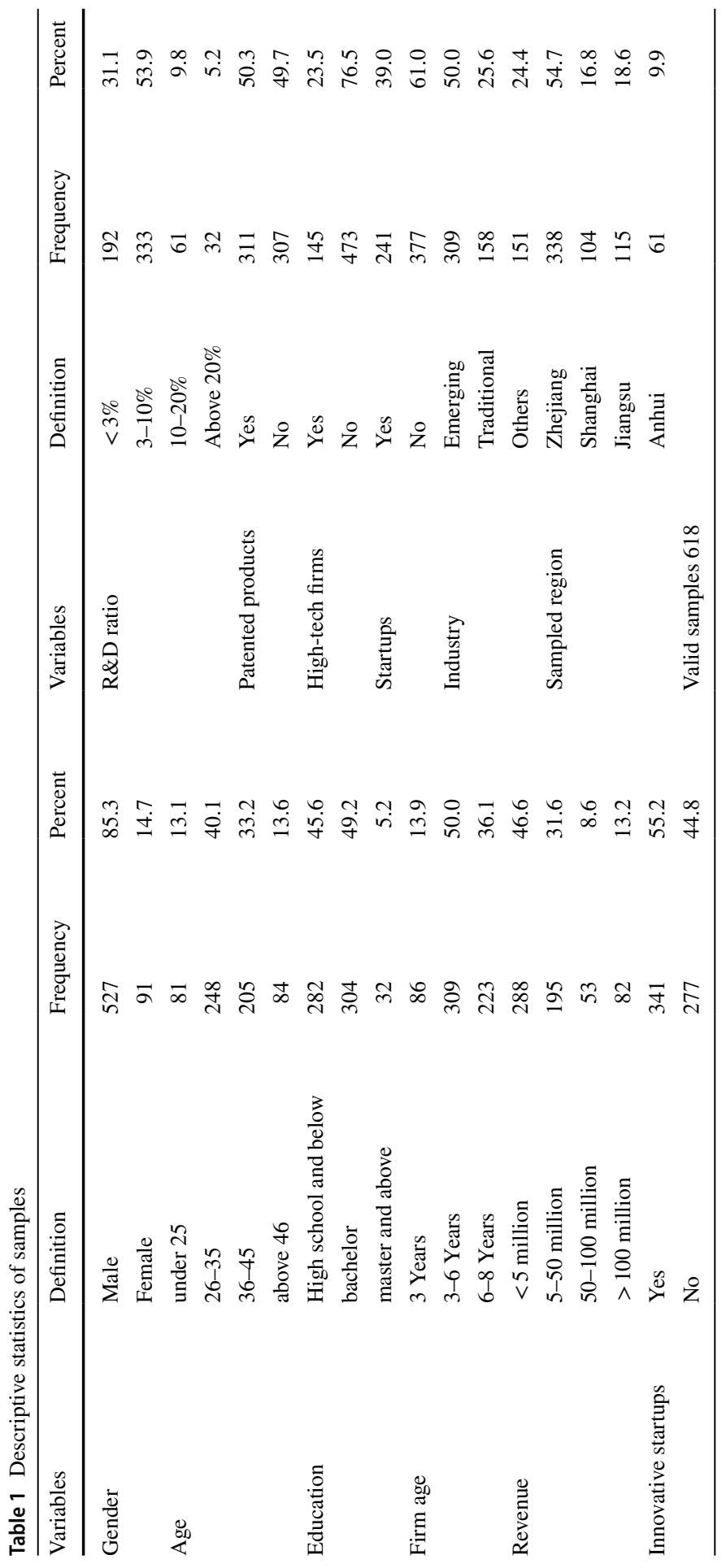




\section{Independent variables}

We measured entrepreneurial networks from the following perspectives: industry types (principal business), cultural background, regional distribution, research direction, and target market. We followed the frameworks suggested by Beckman and Haunschild (2002), Möller and Halinen (2000), and Wang et al. (2012). Next, we identified the networks' characteristics with the five perspectives, according to the scores, and measured the degree of startups' heterogeneous and homogeneous networks. We asked each respondent to answer the question, "Are your close networking relationships found in different industries, research fields, regions, or targeted markets?" Using their assessment, we measured their networks' heterogeneous levels; for example, if any scored 1 (strongly disagree) to all these five questions, we then measured their heterogeneous network as 1. Correspondingly, we also asked questions about their close networking relationship with those in similar industries, research fields, and so forth. Such investigation captured each respondents' heterogeneous and homogeneous networks' scores ranging between 1 and 5.

\section{Mediating variables}

We applied Christensen's (1997) classical definition of disruptive innovation and measured it from six parameters. The survey collected information about firms' strategies in exploring the market and developing new products and business models. With this information, we are able to measure the disruptiveness levels of the startups. In the survey, we asked the startups about their innovation strategy in the last 5 years. The questions included, did your firm "restructure the business model, extend the market, reform the value chain, introduce new concepts without updating technology, and introduce new products?" Or, did your firm "attract and satisfy the mainstream, low-end customers and ignore the inclusion of new products or services?" See Table 2 for detailed survey questions.

\section{Control variables}

Besides the independent variables mentioned in Sect. "Independent variables"., other factors, such as a firm's age, revenue, research and development (R\&D) ratio, entrepreneurial experience, and industry type, may impact startups' performance (Senyard et al., 2011). We set those factors as control variables. Firm age equaled the survey year minus the founded year. Revenue was measured by annual sales; the $R \& D$ ratio was the proportion of $R \& D$ expenses to sales. We set entrepreneurial experience as a dummy variable: the first entrepreneurship equaled 0 , and the rest equaled 1 . Industry type also was a dummy variable, and we assigned 0-5 to the industries of information and communication, new energy and environmental protection, chemistry and manufacturing, biopharmaceutics, textiles, and others. 


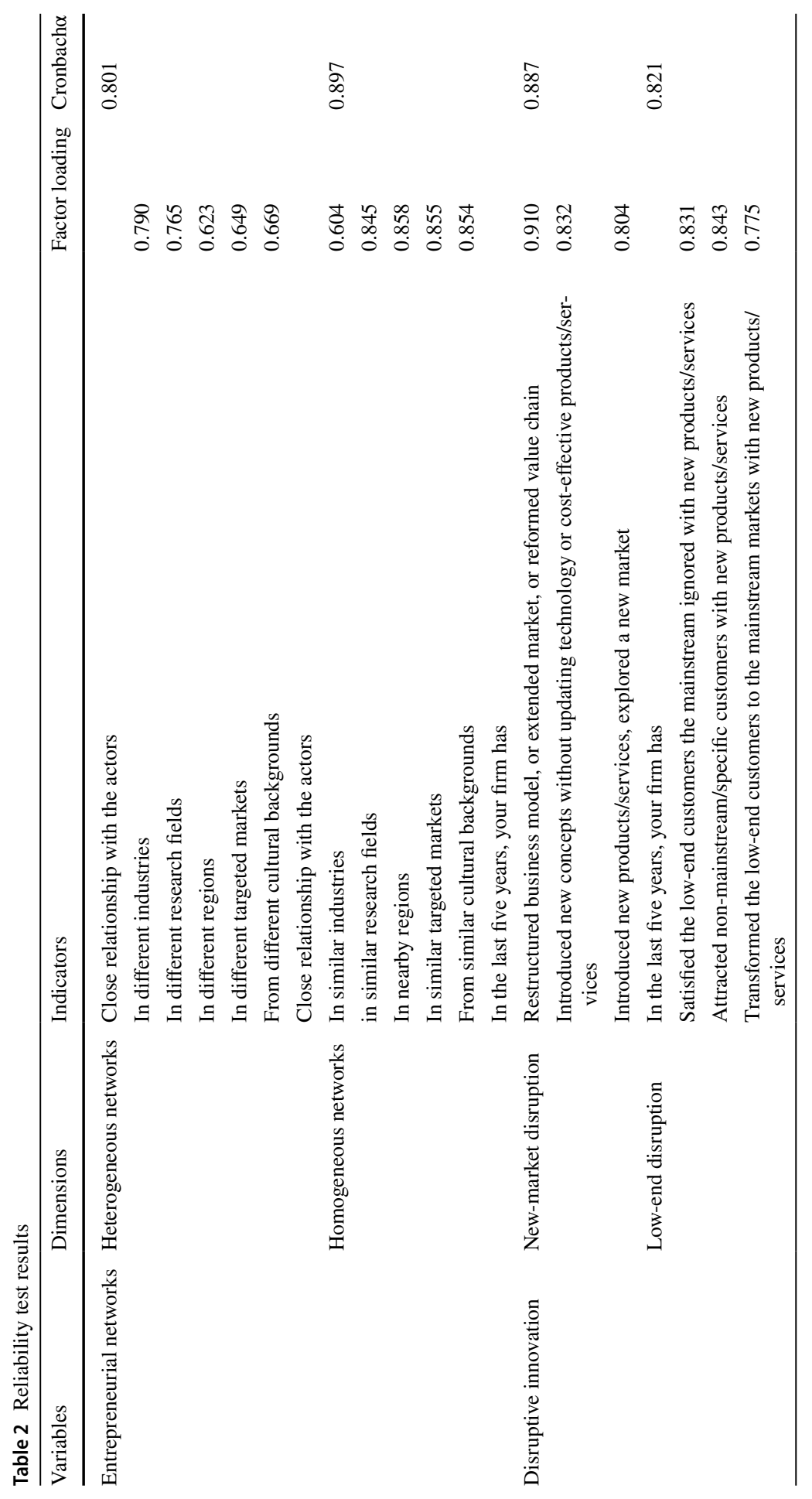




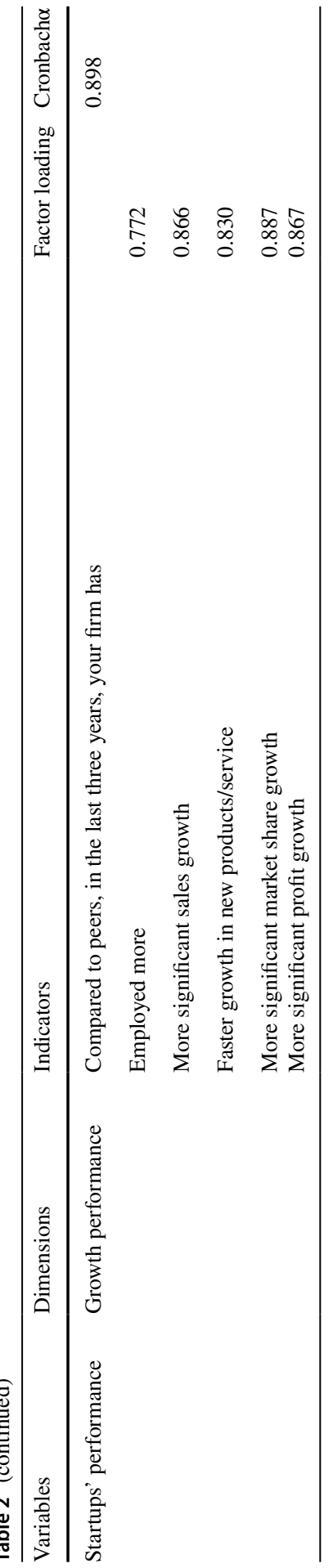

站 


\section{Results}

\section{Reliability of measures}

In order to ensure the reliability of the questionnaire data, we applied different tools to test the validity of variables and confirmed that the data is suitable for factor analysis. The results are shown in Table 2. The factor loading of all items is greater than 0.6, and Cronbach's Alpha values of each factor are more significant than 0.7 (Cronbach, 1951). The Kaiser-Meyer-Olkin (KMO) test and Bartlett spherical tests were performed on the factors. The results show that the KMO values of each variable are greater than 0.7 , and the Bartlett spherical test results are significantly different from 0 , suggesting suitability for factor analysis and that the dataset has appropriate consistency, reliability, and structural validity.

Additionally, to reduce and evaluate the magnitude of common method bias, we applied the procedures suggested in Podsakoff et al. (2003). First, we applied the Harman single factor test to prove structural validity to exclude the common variance of all variables. The results showed that the variance contribution rate is $24.1 \%$, less than $40 \%$. Thus, the common variance problem in this study does not exist. Second, we conducted confirmatory factor analyses (CFA) by loading all factors. A three-factor model showed a superior fit to the data $\left(\Delta \chi^{2} / \Delta f=2.63\right.$, CFI $=0.917$, $\mathrm{TLI}=0.909, \mathrm{RMSEA}=0.063, \mathrm{SRMR}=0.058$ ). Adding an additional method factor did not bring significant change to model fit. Overall, these results suggested little threat of common method bias, and we could proceed with regression analysis and hypothesis testing.

\section{Correlation analysis}

Table 3 shows the Pearson correlation analysis of each variable. There is no significant multicollinearity problem because the correlation coefficient between the variables is much smaller than the critical criterion of 0.7 . There is a positive correlation between the respective variables (6-9) and the dependent variable (10), which provides preliminary evidence for this study's hypothesis validation and further causality identification.

There are negative correlations between firm age and the two types of disruptive innovation, which indicate that relatively small-scale startups are more inclined to carry out disruptive innovation. This finding is consistent with the well-accepted conclusions: large firms (teams) often are conservative due to the high cost of failure; small firms (teams) are more likely to take risks and employ disruptive innovation (Wu et al., 2019). Meanwhile, it also helps explain that $90 \%$ of disruptive innovations are created by SMEs (Chen et al., 2017). R\&D ratio and disruptive innovation are also negatively correlated, which indicates that firms with low R\&D expenses may carry out more disruptive innovation.

The mean value of firms' performance is 2.56 , indicating that although the entrepreneurial activity index in the Yangtze River Delta region is relatively high, the 


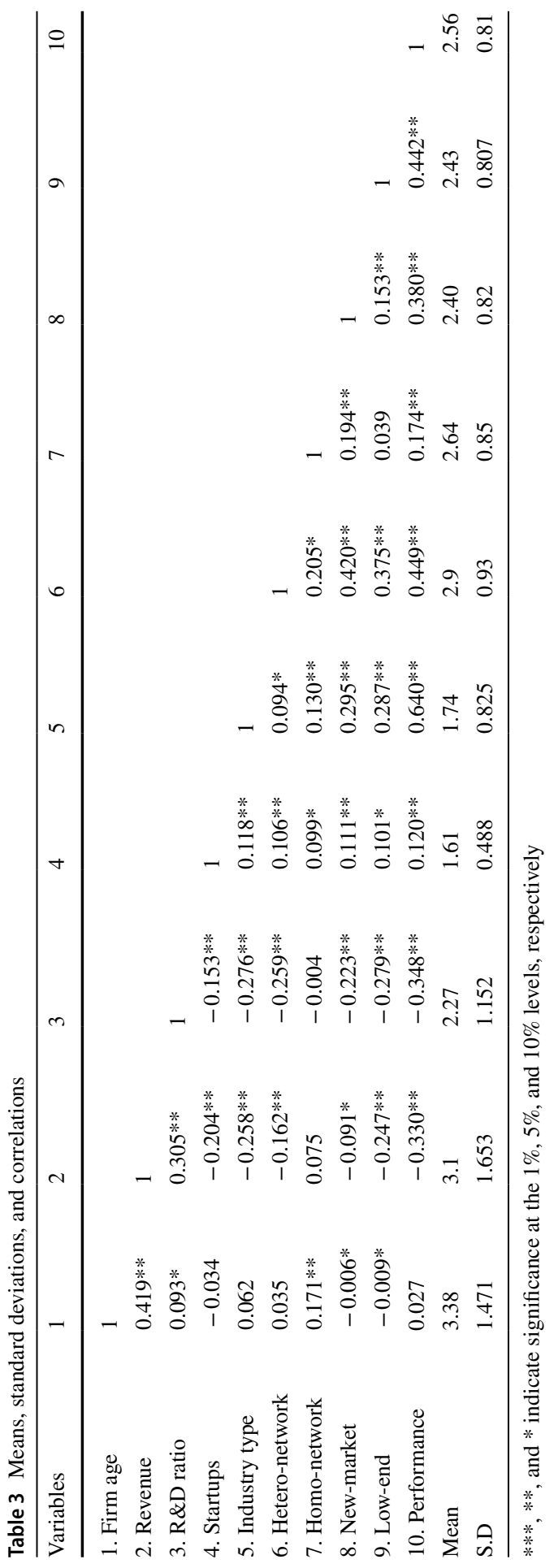


overall growth effect is unsatisfactory. The mean value of the entrepreneurial networks and disruptive innovation is at a low level, which indicates that the establishment of entrepreneurial networks in entrepreneurial practice in China is not well developed, and a disruptive innovation-driven model should be encouraged.

\section{Regression results}

Before running the regression analysis, we diagnosed the collinearity problem. The results show that the VIF values of all control variables and independent variables are below 10, indicating that the collinearity problem is nonexistent. The regression analysis results are shown in Table 4.

Model 6 confirms that both homogeneous networks $(\beta=0.170, P<0.05)$ and heterogeneous networks $(\beta=0.325, P<0.05)$ significantly and positively affect startups' growth. Therefore, Hypotheses H1a and H1b, and accordingly, H1, are confirmed. Furthermore, the heterogeneous networks' impact is greater than the homogeneous networks. The control variables present significant impacts on startups' performance; however, such impacts become less as considering entrepreneurial networks in the regression. Hence, our results suggest that both types of entrepreneurial networks contribute to the growth of startups. Model 7 shows that both low-end disruption $(\beta=0.413, P<0.05)$ and new-market disruption $(\beta=0.386$, $P<0.05)$ positively impact startups' growth significantly, which supports Hypotheses $\mathrm{H} 2 \mathrm{a}$ and $\mathrm{H} 2 \mathrm{~b}$.

Model 2 shows that heterogeneous networks significantly affect low-end disruption $(\beta=0.294, P<0.05)$, whereas homogeneous networks do not present such significance $(\beta=0.039, P>0.1)$, considering entrepreneurial networks in the regression reduces the impacts of control variables on low-end disruption. Hence, empirical results support $\mathrm{H} 3 \mathrm{a}$ but do not support $\mathrm{H} 3 \mathrm{c}$. In the new-market disruption scenario, both heterogeneous $(\beta=0.388, P<0.05)$ and homogeneous $(\beta=0.196$, $P<0.05)$ networks present positive and significant impacts on startup performance, which confirm Hypotheses $\mathrm{H} 3 \mathrm{~b}$ and $\mathrm{H} 3 \mathrm{~d}$. Control variables, revenue, and $\mathrm{R} \& \mathrm{D}$ ratio, do not affect new-market disruption. And again, entrepreneurial networks reduces the impacts of the significant control variables. See Model 4.

We included low-end disruptive innovation in Model 8, and this regression shows that low-end disruptive innovation significantly reduces the effects of the heterogeneous networks on the firms' performance $(\beta=0.283, P<0.05)$. This finding supports hypothesis $\mathrm{H} 4 \mathrm{a}$ and confirms the mediation role of low-end disruption and rejects the hypothesis H4b in the context of homogeneous networks. Similarly, Model 9 demonstrates that new-market disruption imposes impacts on the relationship between variables; thus, Hypotheses $\mathrm{H} 4 \mathrm{c}$ and $\mathrm{H} 4 \mathrm{~d}$ are supported. Overall, these findings confirm the mediating role of disruptive innovation paths between entrepreneurial networks and startups' growth, supporting the mediation effect hypotheses.

We further applied the bootstrap approach to identify the mediation effect (Preacher \& Hayes, 2008). If the total effect is significant, we can assume there might be an indirect effect that quantifies a mediation effect. Table 5 shows the results. In the scenario of heterogeneous networks, the total effect is significant, as 


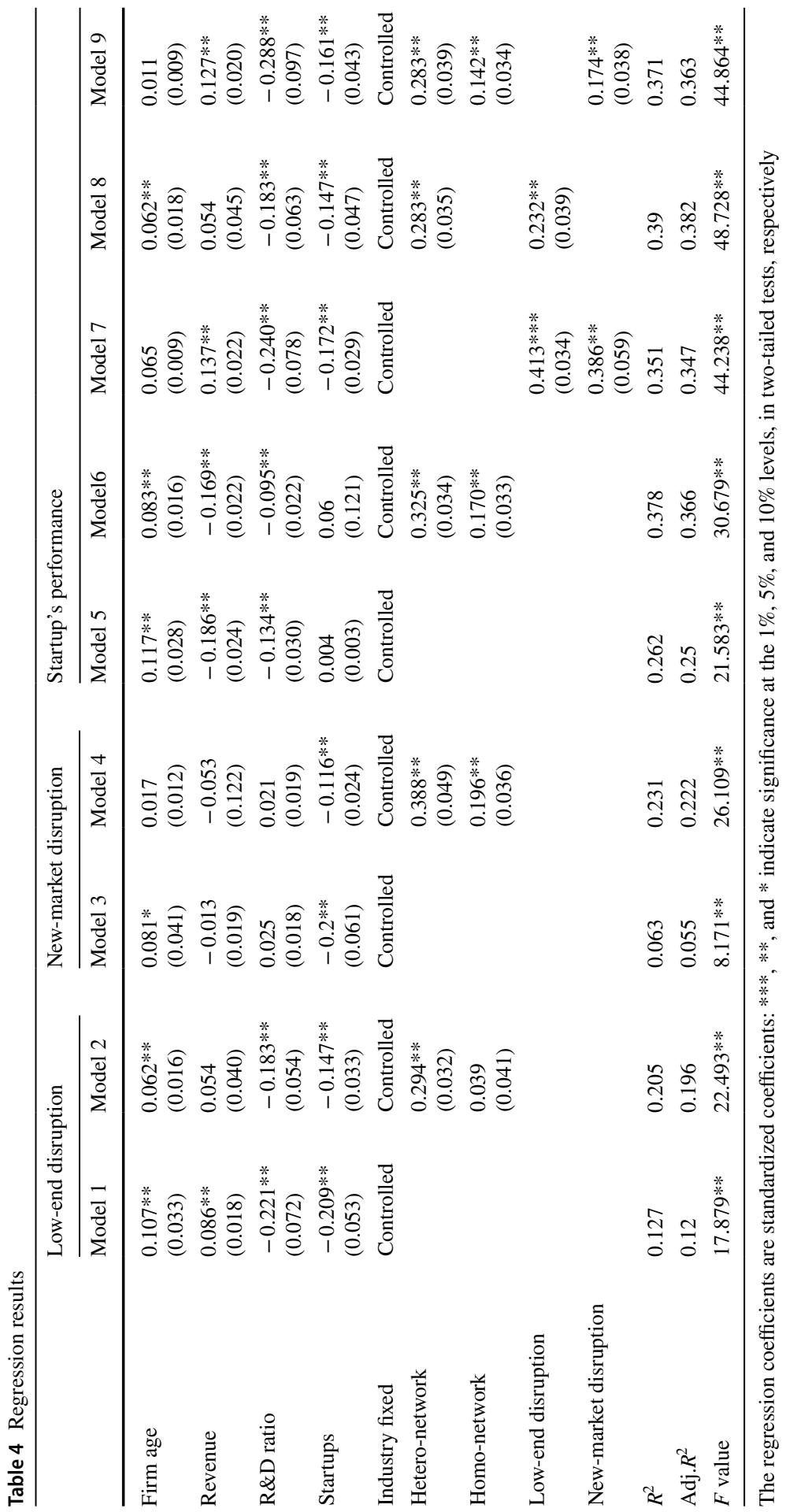




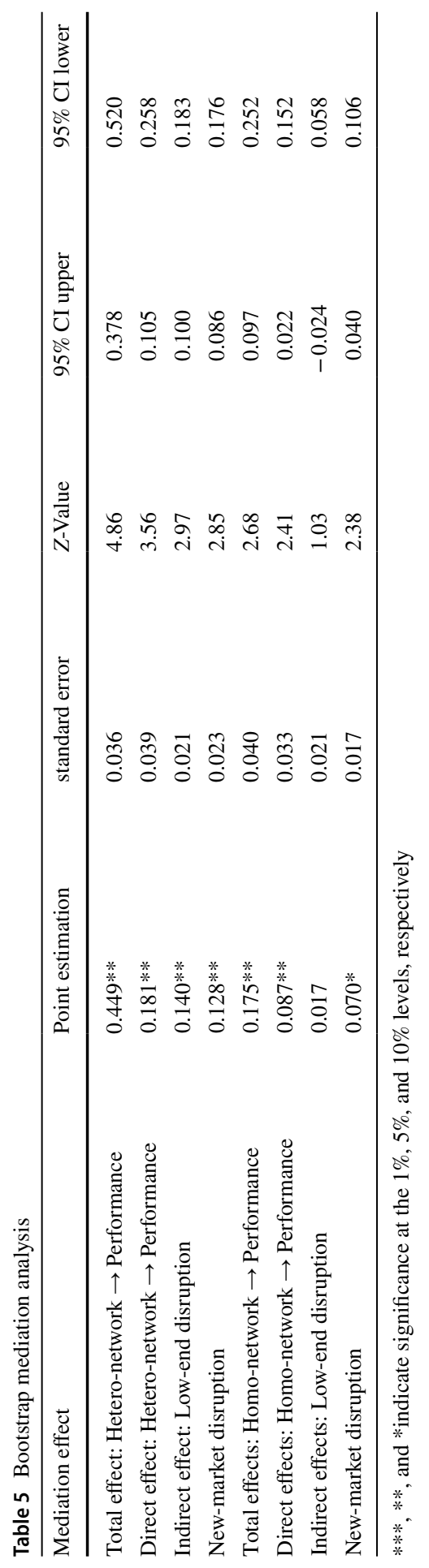


a bias-corrected bootstrapped confidence interval with 5000 samples is above zero, 95\% CI [0.378, 0.520], suggesting that the indirect effect might exist. The direct effect of heterogeneous networks on performance is also significant, with $95 \% \mathrm{CI}$ $[0.105,0.258]$ that is above zero and $Z$-value is greater than 1.96. Both low-end disruption and new-market disruption present significant indirect effects, with the conditions of $95 \%$ CI [0.100, 0.183] and 95\% CI [0.086, 0.176], respectively, indicating that $\mathrm{H} 4 \mathrm{a}$ and $\mathrm{H} 4 \mathrm{c}$ are supported.

In the scenario of homogeneous networks, the total effect is significant, as a bias-corrected bootstrapped confidence interval with 5000 samples is above zero, 95\% CI [0.097, 0.252], suggesting the indirect effect might exist as well. The direct effect of homogeneous networks on performance is significant, with 95\% CI [0.022, 0.152 ] that is above zero and $Z$-value is greater than 1.96 . However, the indirect effect of low-end disruption is not significant, with $95 \% \mathrm{CI}[-0.024,0.058]$ that is out of positive interval and $Z$-value is less than 1.96, indicating that $\mathrm{H} 4 \mathrm{~b}$ is not supported; whereas the indirect effect of new-market disruption is supported, with $95 \%$ CI $[0.040,0.106]$ that is above zero and Z-value is greater than 1.96. The results of bootstrap mediation analysis are consistent with those using stepwise regression.

\section{Discussion}

\section{The impacts of entrepreneurial networks}

Our regression estimation confirms the positive significance of entrepreneurial networks on startups' growth and that heterogeneous networks play a more significant role than homogeneous ones. These findings are consistent with the mainstream conclusion that excludes the significance of homogeneous networks (Elfring \& Hulsink, 2003; Rodan, 2004). Heterogeneous networks may diversify knowledge, resources, and information for networking firms and, in turn, may extend the possibility of success (Grigoriou \& Rothaermel, 2017; Smith \& Tushman, 2005).

\section{Matching entrepreneurial networks and disruptive innovation paths}

Startups must match the limited resources with their growth and survival targets at the early entrepreneurial stage and must be aware that networking is costly (Autio et al., 2014; Zhao \& Aram, 1995). Leading incumbents usually control the mainstream profitable market sections. Nevertheless, the leaders may face difficulties in responding to technological innovation, as they must be careful about the opportunity cost to introduce new products and explore new markets (Wesseling et al., 2015). The new-market disruption focuses on creating a new value proposition and establishing new values for long-tail customers. Such an entrepreneurial strategy features the significance of disruptive innovation, which may enable startups to adopt a distinctive path from the incumbents, eventually catching up with them (Christensen et al., 2018). 
Networking strategies must match with the specific innovation strategies. Networking with various technologies, knowledge, information, and opportunities enables startups to translate external resources into internal ones, even from their homogeneous peers. However, rejecting Hypothesis H3c might suggest that homogeneous networks cannot differentiate startups from their connections in the low-end market, as most firms embedded in low-end networks are unable to break the existing technological trajectories (Hynes \& Elwell, 2016). In other words, in the lowend market, homogeneous networking startups and incumbents compete with each other, and the startups only imitate the incumbents and do not extend and create a new market. Accordingly, the mediation effect of disruption paths in the context of homogeneous networks is not supported either.

\section{Theoretical contributions}

Scholarly literature agrees that entrepreneurial networks, as a dynamic and nonbounded flexible organization structure, provide knowledge and capacities that enable startups to catch up with technological frontiers and gain market shares (Dyer \& Singh, 1998; Majumdara et al., 2018; Uzzi, 1999). Entrepreneurial practices also confirm the significance of entrepreneurial networks on implementing disruptive innovation (Zhao \& Aram, 1995).

However, considering new-market disruptive innovation, we find that homogeneous networking also plays a significant role in startups' growth, which contradicts the classic entrepreneurship literature (e.g., Xie \& Zuo, 2013) but is consistent with the effectuation logic that argues that "whom I know" networks are more crucial for entrepreneurial endeavor (Kerr \& Coviello, 2020; Sarasvathy, 2001). We suggest the reason for this new result lies in the present study's sampling of firms, which differs from other studies that included incumbents. Our firms are exclusively "young, small, and feeble" startups that can benefit from homogeneous networks, whereas the mature incumbents are trying to keep a distance from homogeneous networking peers. Hence, at a venture's early stage, startups may present distinctive networking needs and behave differently in response to external resources that seem to be inapplicable and redundant for mature firms.

The asymmetric mediation effects suggest that startups that aim at exploring the low-end market must explore and specify a niche market and differentiate from networking peers; otherwise, they may face difficulties competing with incumbents. However, if startups devote efforts to creating new and novelty markets, heterogeneous networks are crucial for diversifying (Amin \& Cohendet, 2000).

\section{Practical implications}

However, not all types of disruptive innovation enjoy homogeneous networks. Our results exhibit a distinctive network effect in low-end disruption and new-market disruption. Homogeneous networks only work positively when the startups aim to explore a new market, whereas heterogeneous networks play significant and positive roles in both low-end and new-market disruptive innovation. Hence, homogeneous peers may 
exchange information and experience, but their overlap in the low-end market may also lead to homogeneous competition. Diversifying the market may help disruptive innovators to utilize and match their networking peers with market demands.

This finding reflects that establishing links to organizations and individuals should consider startups' immediate needs. Organizational survival and development rely on strategic options and the efforts made to achieve certain effectuation results (Prashantham et al., 2019). More importantly, however, survival and development depend on how aims and efforts are matched (Tan, 2002). The matching argument suggests that entrepreneurs' initial endowments in social networks have endogenously impacted how successful their firms can be at least at the early stage. However, strategically establishing networks according to their aims is even more essential (Ozcan \& Eisenhardt, 2009; Suseno, 2018). A favorable network structure enables firms to access resources from the right networking peers at a low cost. A new-market disruption firm may concentrate on corresponding to the connected vertical values intensively and establishing networks with the local institutes and entrepreneurs with comprehensive knowledge about the new market. Dai et al. (2019) have documented that, as institutional setup changes, networking startup behavior in China also presents various features. For example, Chinese entrepreneurs grew less interested in connecting political networks that may be more relevant for long-term growth but have little impacts as their firms are young. Instead, they increasingly concentrated on conventional business resources and invest less in political connections (Burt \& Opper, 2020).

\section{Limitations and future research}

Nevertheless, our research has limitations. It would be more insightful to test the interaction effects between homogeneous and heterogeneous networks on disruptive innovation and startups' growth. Furthermore, we only investigated the variables at the firm level and did not discuss institutional setup and entrepreneurial environment, which are essential for disruptive innovation as well. Additionally, our data did not classify industrial sectors or entrepreneurial motivation, which are also relevant. Regarding future research, we may consider extending our dataset in the following years and track the growth trajectories. We can also conduct case studies with our sampling firms. Future research also may extend and justify our findings via alternative research designs and methods. For instance, we adopted subjective comparative performance measurement that has been widely in the literature in the last decades; however, if our investigated companies release their reliable financial data in the future, it would be a great chance to compare these two data collection methods. 


\section{Conclusion}

This study started with a perception of entrepreneurial effectuation and investigated how entrepreneurial networks can be integrated into the specific context of disruptive activities via looking into disruptive innovation paths' mediation effects. First, we found that both entrepreneurial networks, i.e., homogeneous networks and heterogeneous networks, and disruptive innovation, i.e., low-end disruption and newmarket disruption, positively affect startups' growth. However, startups should be careful choosing a disruptive path; the results suggest either new-market disruption or low-end disruption creates benefits for startups to make a breakthrough, but homogenous networks may weaken the startups in the low-end market characterized by a dearth of sufficient heterogeneous competitiveness among the networking peers. Second, we identified that both types of networking efforts, in general, can help the firm's growth. This finding contradicts the existing literature that suggests firms should avoid homogeneous peers. With this finding, we argued that startups may present distinctive networking needs considering survival targets at the early entrepreneurial stage, whereas the mature incumbents who dislike networking with homogeneous peers. Third, we studied the mediation effect of disruptive innovation paths on the association between entrepreneurial networks and startups' growth. The existing literature has rarely investigated how disruptive innovation becomes an organizational capacity in the entrepreneurial process from dynamic perspectives. We found that startups that explore low-end disruption may benefit more from heterogeneous peers and avoid networking with abundant homogeneous peers. However, if exploring new markets, both types of networks could provide positive impacts. Exploring a low-end market is a practical disruptive option for young firms to accumulate capital, experience, knowledge, and market; however, in this context, homogeneous networking peers cannot provide considerable benefits because comparing the positive spillover on networks, competition among them may significantly reduce survival space.

Acknowledgements This research was supported by Key Project of Soft Science Research Program of Zhejiang Province, China (No.2021C25003), Projects of the National Social Science Foundation of China (Grant No.17BGL043), the National Social Science Foundation of China (No.20BJY100).

Funding Open Access funding enabled and organized by Projekt DEAL.

Open Access This article is licensed under a Creative Commons Attribution 4.0 International License, which permits use, sharing, adaptation, distribution and reproduction in any medium or format, as long as you give appropriate credit to the original author(s) and the source, provide a link to the Creative Commons licence, and indicate if changes were made. The images or other third party material in this article are included in the article's Creative Commons licence, unless indicated otherwise in a credit line to the material. If material is not included in the article's Creative Commons licence and your intended use is not permitted by statutory regulation or exceeds the permitted use, you will need to obtain permission directly from the copyright holder. To view a copy of this licence, visit http://creativecommons.org/licen ses/by/4.0/. 


\section{References}

Aldrich, H., \& Zimmer, C. (1986). Entrepreneurship through social networks. In D. L. Sexton \& R. W. Smilor (Eds.), The art and science of entrepreneurship (pp. 3-23). Ballinger.

Amin, A., \& Cohendet, P. (2000). Organizational learning and governance through embedded practices. Journal of Management and Governance, 4(1-2), 93-116.

Autio, E., Kenney, M., Mustar, P., Siegel, D., \& Wright, M. (2014). Entrepreneurial innovation: The importance of context. Research Policy, 43(7), 1097-1108.

Baron, R. A., \& Tang, J. (2011). The role of entrepreneurs in firm-level innovation: Joint effects of positive affect, creativity, and environmental dynamism. Journal of Business Venturing, 26(1), 49-60.

Baum, J. R., Locke, E. A., \& Smith, K. G. (2001). A multidimensional model of venture growth. Academy of Management Journal, 44(2), 292-303.

Beckman, C. M., \& Haunschild, P. R. (2002). Network learning: The effects of partners' heterogeneity of experience on corporate acquisitions. Administrative Science Quarterly, 47(1), 92-124.

Burt, R. S., \& Opper, S. (2020). Political connection and disconnection: Still a success factor for Chinese entrepreneurs. Entrepreneurship Theory and Practice, 44(6), 1199-1228.

Carayannis, E. G., \& von Zedtwitz, M. (2005). Architecting gloCal (global-local), real-virtual incubator networks (G-RVINs) as catalysts and accelerators of entrepreneurship in transitioning and developing economies: Lessons learned and best practices from current development and business incubation practices. Technovation, 25(2), 95-110.

Cardon, M. S., Post, C., \& Forster, W. R. (2017). Team entrepreneurial passion: Its emergence and influence in new venture teams. Academy of Management Review, 42(2), 283-305.

Chen, J., Zhu, Z., \& Zhang, Y. (2017). A study of factors influencing disruptive innovation in Chinese SMEs. Asian Journal of Technology Innovation, 25(1), 140-157.

Christensen, C. M. (1997). The innovator's dilemma: When new technologies cause great firms to fail. Harvard Business School Press.

Christensen, C. M. (2006). The ongoing process of building a theory of disruption. Journal of Product Innovation Management, 23(1), 39-55.

Christensen, C. M., Johnson, C. W., \& Horn, M. B. (2010). Disrupting class. McGraw-Hill.

Christensen, C. M., Johnson, M. W., \& Rigby, D. K. (2002). Foundations for growth how to identify and build disruptive new businesses. MIT Sloan Management Review, 43(3), 22-32.

Christensen, C. M., McDonald, R., Altman, E. J., \& Palmer, J. E. (2018). Disruptive innovation: An intellectual history and directions for future research. Journal of Management Studies, 55(7), 1043-1078.

Christensen, C. M., \& Raynor, M. E. (2003). Why hard-nosed executives should care about management theory. Harvard Business Review, 81(9), 66-75.

Christensen, C. M., Raynor, M. E., \& McDonald, R. (2015). What is disruptive innovation? Harvard Business Review, 12, 44-53.

Corsaro, D., Cantù, C., \& Tunisini, A. (2012). Actors' heterogeneity in innovation networks. Industrial Marketing Management, 41(5), 780-789.

Cozzolino, A., Verona, G., \& Rothaermel, F. T. (2018). Unpacking the disruption process: New technology, business models, and incumbent adaptation. Journal of Management Studies, 55(7), 1166-1202.

Cronbach, L. (1951). Coefficient alpha and the internal structure of tests. Psychomerika, 16, 297-334.

Dai, S., \& Taube, M. (2020). The long tail thesis: Conceptualizing China's entrepreneurial practices in fintech and electric vehicles. Chinese Management Studies, 14(2), 433-454.

Dai, S., Wang, Y., \& Liu, Y. (2019). The emergence of Chinese entrepreneurs: Social connection and innovation. Journal of Entrepreneurship in Emerging Economies, 11(3), 351-368.

Dedehayir, O., Nokelainen, T., \& Mäkinen, S. J. (2014). Disruptive innovations in complex product systems industries: A case study. Journal of Engineering and Technology Management, 33, 174-192.

Dyer, J. H., \& Singh, H. (1998). The relational view: Cooperative strategy and sources of interorganizational competitive advantage. Academy of Management Journal, 23(4), 660-679.

Elfring, T., \& Hulsink, W. (2003). Networks in entrepreneurship: The case of high-technology firms. Small Business Economics, 21(4), 409-422.

Engel, Y., Kaandorp, M., \& Elfring, T. (2017). Toward a dynamic process model of entrepreneurial networking under uncertainty. Journal of Business Venturing, 32(1), 35-51. 
Forbes, D. P., Borchert, P. S., Zellmer-Bruhn, M. E., \& Sapienza, H. J. (2006). Entrepreneurial team formation: An exploration of new member addition. Entrepreneurship Theory and Practice, 30(2), 225-248.

Goerzen, A., \& Beamish, P. W. (2005). The effect of alliance network diversity on multinational enterprise performance. Strategic Management Journal, 26(4), 333-354.

Grigoriou, K., \& Rothaermel, F. T. (2017). Organizing for knowledge generation: Internal knowledge networks and the contingent effect of external knowledge sourcing. Strategic Management Journal, 38(2), 395-414.

Gulati, R. (1999). Network location and learning: The influence of network resources and firm capabilities on alliance formation. Strategic Management Journal, 20(5), 397-420.

Hite, J. M., \& Hesterly, W. S. (2001). The evolution of firm networks: From emergence to early growth of the firm. Strategic Management Journal, 22(3), 275-286.

Hoang, H., \& Antoncic, B. (2003). Network-based research in entrepreneurship: A critical review. Journal of Business Venturing, 18(2), 165-187.

Hynes, N., \& Elwell, A. D. (2016). The role of inter-organizational networks in enabling or delaying disruptive innovation: A case study of mVoIP. Journal of Business \& Industrial Marketing, 31(6), $722-731$.

Kaandorp, M., van Burg, E., \& Karlsson, T. (2020). Initial networking processes of student entrepreneurs: The role of action and evaluation. Entrepreneurship Theory and Practice, 44(3), 527-556.

Kenagy, J. W., \& Christensen, C. M. (2002). Disruptive innovation: A new diagnosis for health care's financial flu. Healthcare Financial Management, 56(5), 62-67.

Kerr, J., \& Coviello, N. (2019). Formation and constitution of effectual networks: A systematic review and synthesis. International Journal of Management Reviews, 21(3), 370-397.

Kerr, J., \& Coviello, N. (2020). Weaving network theory into effectuation: A multi-level reconceptualization of effectual dynamics. Journal of Business Venturing, 35(2), 105937.

Kumaraswamy, A., Garud, R., \& Ansari, S. (2018). Perspectives on disruptive innovations. Journal of Management Studies, 55(7), 1025-1042.

Landry, R., Amara, N., \& Lamari, M. (2002). Does social capital determine innovation? To what extent? Technological Forecasting and Social Change, 69(7), 681-701.

Lin, J., \& Si, S. (2010). Can guanxi be a problem? Contexts, ties, and some unfavorable consequences of social capital in China. Asia Pacific Journal of Management, 27, 561-582.

Majumdar, D., Banerji, P. K., \& Chakrabarti, S. (2018). Disruptive technology and disruptive innovation: Ignore at your peril! Technology Analysis \& Strategic Management, 30(11), 1247-1255.

Martinez, M. A., \& Aldrich, H. E. (2011). Networking strategies for entrepreneurs: Balancing cohesion and diversity. International Journal of Entrepreneurial Behavior \& Research, 17(1), 7-38.

Molina-Morales, F. X., \& Martínez-Fernández, M. T. (2010). Social networks: Effects of social capital on firm innovation. Journal of Small Business Management, 48(2), 258-279.

Möller, K., \& Halinen, A. (2000). Relationship marketing theory: Its roots and direction. Journal of Marketing Management, 16(1), 29-54.

Ozcan, P., \& Eisenhardt, K. M. (2009). Origin of alliance portfolios: Entrepreneurs, network strategies, and firm performance. Academy of Management Journal, 52(2), 246-279.

Ozdemir, S. Z., Moran, P., Zhong, X., \& Bliemel, M. J. (2016). Reaching and acquiring valuable resources: The entrepreneur's use of brokerage, cohesion, and embeddedness. Entrepreneurship Theory and Practice, 40(1), 49-79.

Park, Y., Shin, J., \& Kim, T. (2010). Firm size, age, industrial networking, and growth: A Case of the Korean manufacturing industry. Small Business Economics, 35(2), 153-168.

Partanen, J., Kauppila, O., Sepulveda, F., \& Gabrielsson, M. (2020). Turning strategic network resources into performance: The mediating role of network identity of small-and medium-sized enterprises. Strategic Entrepreneurship Journal, 14(2), 178-197.

Perry-Smith, J. E., \& Mannucci, P. V. (2015). Social networks, creativity, and entrepreneurship. In C. E. Shalley, M. A. Hitt, \& J. Zhou (Eds.), The Oxford handbook of creativity, innovation, and entrepreneurship (pp. 205-224). Oxford University Press.

Phelps, C. C. (2010). A longitudinal study of the influence of alliance network structure and composition on firm exploratory innovation. Academy of Management Journal, 53(4), 890-913.

Podsakoff, P. M., MacKenzie, S. B., Lee, J. Y., \& Podsakoff, N. P. (2003). Common method biases in behavioral research: A critical review of the literature and recommended remedies. Journal of Applied Psychology, 88(5), 879. 
Porter, C. M., \& Woo, S. E. (2015). Untangling the networking phenomenon: A dynamic psychological perspective on how and why people network. Journal of Management, 41(5), 1477-1500.

Prashantham, S., Kumar, K., Bhagavatula, S., \& Sarasvathy, S. D. (2019). Effectuation, network-building and internationalisation speed. International Small Business Journal, 37(1), 3-21.

Preacher, K. J., \& Hayes, A. F. (2008). Asymptotic and resampling strategies for assessing and comparing indirect effects in multiple mediator models. Behavior Research Methods, 40(3), 879-891.

Rodan, S., \& Galunic, C. (2004). More than network structure: How knowledge heterogeneity influences managerial performance and innovativeness. Strategic Management Journal, 25(6), 541-562.

Rogers, M. (2004). Networks, firm size and innovation. Small Business Economics, 22(2), 141-153.

Sarasvathy, S. D. (2001). Causation and effectuation: Toward a theoretical shift from economic inevitability to entrepreneurial contingency. Academy of Management Review, 26(2), 243-263.

Sarasvathy, S. D. (2008). Effectuation: Elements of entrepreneurial experience. Edward Elgar.

Schilling, M. A., \& Phelps, C. C. (2007). Interfirm collaboration networks: The impact of large-scale network structure on firm innovation. Management Science, 53(7), 1113-1126.

Schoonjans, B., Van Cauwenberge, P., \& Vander Bauwhede, H. (2013). Formal business networking and SME growth. Small Business Economics, 41(1), 169-181.

Senyard, J. M., Baker, T., \& Davidsson, P. (2011). Bricolage as a path to innovation for resource constrained new firms. In Academy of Management Proceedings (Vol. 2011, No. 1, pp. 1-5). Briarcliff Manor: Academy of Management.

Shu, R., Ren, S., \& Zheng, Y. (2018). Building networks into discovery: The link between entrepreneur network capability and entrepreneurial opportunity discovery. Journal of Business Research, 85, 197-208.

Singh, S., Darwish, T. K., \& Potočnik, K. (2016). Measuring organizational performance: A case for subjective measures. British Journal of Management, 27(1), 214-224.

Smith, E. B., Menon, T., \& Thompson, L. (2012). Status differences in the cognitive activation of social networks. Organization Science, 23(1), 67-82.

Smith, W. K., \& Tushman, M. L. (2005). Managing strategic contradictions: A top management model for managing innovation streams. Organization Science, 16(5), 522-536.

Soh, P. H., \& Roberts, E. B. (2003). Networks of innovators: A longitudinal perspective. Research Policy, 32(9), 1569-1588.

Stam, W., Arzlanian, S., \& Elfring, T. (2014). Social capital of entrepreneurs and small firm performance: A meta-analysis of contextual and methodological moderators. Journal of Business Venturing, 29(1), 152-173.

Stuart, T. E., \& Sorenson, O. (2007). Strategic networks and entrepreneurial ventures. Strategic Entrepreneurship Journal, 1(3-4), 211-227.

Suseno, Y. (2018). Disruptive innovation and the creation of social capital in Indonesia's urban communities. Asia Pacific Business Review, 24(2), 174-195.

Tan, J. (2002). Impact of ownership type on environment-strategy linkage and performance: Evidence from a transitional economy. Journal of Management Studies, 39(3), 333-354.

Uzzi, B. (1997). Social structure and competition in interfirm networks: The paradox of embeddedness. Administrative Science Quarterly, 42(1), 35-67.

Uzzi, B. (1999). Embeddedness in the making of financial capital: How social relations and networks benefit firms seeking financing. American Sociological Review, 64(4), 481-505.

Wang, K. Y., Wang, Y., Huang, K.-P., \& Deng, J. (2012). Heterogeneous networks and resource acquisition of SMEs in emerging economies. Quality \& Quantity, 46(5), 1643-1657.

Watson, J. (2007). Modeling the relationship between networking and firm performance. Journal of Business Venturing, 22(6), 852-874.

Watson, W. E., Kumar, K., \& Michaelsen, L. K. (1993). Cultural diversity's impact on interaction process and performance: Comparing homogeneous and diverse task groups. Academy of Management Journal, 36(3), 590-602.

Wesseling, J. H., Niesten, E. M., Faber, J., \& Hekkert, M. P. (2015). Business strategies of incumbents in the market for electric vehicles: Opportunities and incentives for sustainable innovation. Business Strategy and the Environment, 24(6), 518-531.

Witt, P. (2004). Entrepreneurs' networks and the success of start-ups. Entrepreneurship \& Regional Development, 16(5), 391-412.

Wu, L., Wang, D., \& Evans, J. A. (2019). Large teams develop and small teams disrupt science and technology. Nature, 566(7744), 378-382. 
Xie, X., \& Zuo, L. (2013). Corporate collaborative innovation network characteristics and innovation performance: A study on the mediating effect based on knowledge absorption capacity. Nankai Business Review, 16(3), 47-56. (in Chinese).

Yu, D., \& Hang, C. C. (2010). A reflective review of disruptive innovation theory. International Journal of Management Reviews, 12(4), 435-452.

Zhang, K., Wang, J., Feng, L., \& Cheng, Y. (2019). The evolution mechanism of latecomer firms value network in disruptive innovation context: A case study of Haier Group. Technology Analysis \& Strategic Management, 31(12), 1488-1500.

Zhao, L., \& Aram, J. D. (1995). Networking and growth of young technology-intensive ventures in China. Journal of Business Venturing, 10(5), 349-370.

Publisher's Note Springer Nature remains neutral with regard to jurisdictional claims in published maps and institutional affiliations. 